\title{
Action plan for tackling violence against older adults in Brazil: analysis of indicators by states
}

Talita Araujo de Souza' Sávio Marcelino Gomes² ${ }^{2}$ (D) Isabelle Ribeiro Barbosa² ${ }^{2}$ D Kenio Costa de Lima² $\mathbb{I D}$

\section{Abstract}

Objective: to analyze the indicators of the action plan for tackling violence against older adults in Brazil, through temporal and spatial trends. Method: all nine indicators that form the plan were taken from the Sistema de Indicadores de Saúde e Acompanhamento de Politicas do Idoso (the Indicators of Health and Monitoring of Policies for Older Adults System). Time trend analysis was applied by Joinpoint Regression (CI95\%), spatial distribution by states and clusters by Ward's hierarchical agglomerative method, using quadratic Euclidean distance. Results: the study indicated a significant trend of an increase in notifications of cases of violence against older adults, of the hospitalization of older adults because of abuse, of the hospitalization of older adults because of femur fractures, of the mortality rate of older adults because of falls and of the hospitalization of older adults because of falls. Five clusters were formed, with two cluster formations standing out: that of the states of Rondonia, Roraima and Tocantins, because of their high levels of hospitalization and mortality by traffic accidents and high levels of mortality by abuse; and that of the states of Espírito Santo, Goias, Mato Grosso do Sul, Parana, Rio Grande do Sul, Sao Paulo and Sergipe, because of their high levels of hospitalization and mortality by falling and fractures, as well as their high level of violence against older adults. Conclusion: records of violence against older adults are increasing in Brazil, with specific types of violence concentrated in specific regions of the country.

\footnotetext{
Universidade Federal do Rio Grande do Norte, Programa de pós-graduação em Ciências da Saúde, Natal, RN, Brasil

2 Universidade Federal do Rio Grande do Norte, Programa de pós-graduação em Saúde Coletiva, Natal, RN, Brasil Departamento
}

No funding was received in relation to the present study

The authors declare there are no conflicts of interest in relation to the present study.

Correspondence

Talita Araujo de Souza

Received: April 15, 2019

talitaaraujo23@hotmail.com
Keywords: Older People. Health of the Elderly. Violence. Health Evaluation. Situational Diagnosis. 


\section{INTRODUCTION}

Violence is considered a phenomenon of complex causality, involving authority, power and domination. Among older adults, it assumes three main general forms: violence directed at older adults, violence directed at the self and collective violence ${ }^{1,2}$.

Factors such as low levels of education, degree of financial dependence, fragility of the social support network, access to compromising information and fear of breaking family ties are associated with the phenomenon of violence in this group, along with morbidities, which lead to a decrease in functional and cognitive capacity and the valuation of older adults, who are often relegated to the margins of society $y^{3,4}$.

Evidence suggests that abuse and the mistreatment of older adults is a global health problem, and related to the diversity of regions, cultures and sociopolitical situations, ranges from $2.2 \%$ to $44.6 \%{ }^{3}$. The combined prevalence rate of general abuse is $15.7 \%$, with $11.6 \%$ for psychological abuse, $6.8 \%$ for financial abuse, $4.2 \%$ for neglect, $2.6 \%$ for physical abuse and $0.9 \%$ for sexual abuse ${ }^{4}$.

In Brazil, women are the main victims of abuse in the older adult population (64\%), with physical (28\%) and psychological $(28 \%)$ violence being the most frequent forms, in which there is, in a large number of cases, a relationship of proximity between the victim and the aggressors. This is especially true for children of the victim (28\%), with the victim's own home being the main location of the abuse $(60 \%)$, and a tendency for cases to increase over the years ${ }^{5}$.

The epidemiological profile, however, may vary between regions, due to the inequalities related to the process of demographic transition in Brazil, which is, in turn, marked by significant differences between regions. The north and northeast regions exhibit a slow evolution in this transition process, while the south, in contrast, presents accelerated growth, corroborating the historical inequalities experienced in Brazil ${ }^{6.7}$.

Therefore, the State has an important role in combating the impact of the structural inequalities that result in the violence suffered by the older population ${ }^{8}$, meaning it is important to carry out sets of actions to maintain a state of social wellbeing, which translate the objectives of governments into the realization of the rights of the population ${ }^{8}$.

Brazil has also undergone a transformation in the concepts of care for the older population, moving from a state of segregation to the recognition of their rights by the Federal Constitution. As a legal framework for health policies for older adults in Brazil, the creation of the Statute for Older Adults and the National Health Policy for Older Adults (or PNSPI) stand out, being responsible for legitimizing rights and guiding the prevention, recovery and preservation of the health of this population?

Other strategies have been incorporated by the State, such as the Action Plan to Combat Violence Against Older Adults, which has the objective of combating social exclusion and all forms of violence against this group, establishing indicators for monitoring the proposed guidelines and highlighting the need to evaluate the plan ${ }^{10}$, a phase inherent to the Public Policy Cycle. In the field of health, evaluation is essential for planning and preparing interventions, as well as reorienting ongoing and future actions ${ }^{11}$.

The indicators are grouped according to the objectives of the plan. To incentivize the adaptation of domestic spaces for older adults, hospitalizations of older adults due to falls and fractures of the femur, the proportion of older adults with difficulty walking at home alone and the mortality of older adults due to falls are evaluated. In order to verify the need for State protection for families, with a view to preventing intrafamily violence, hospitalizations and mortality of older adults due to mistreatment and reports of violence are evaluated. Finally, the evaluation of hospitalizations and mortality of older adults due to traffic accidents aim to promote necessary adaptations to the public space ${ }^{12}$.

Evaluating indicators of violence, therefore, contributes to the understanding of this phenomenon throughout Brazil, taking into account historical regional inequalities and the impact of the demographic transition in the country, allowing the State to provide adequate care in the aging process. Thus, the present study aims to analyze 
the indicators that make up the Action Plan to Combat Violence Against Older Adults in Brazil, in an attempt to understand this phenomenon from temporal and spatial trends.

\section{METHOD}

The database used was compiled from data available in the Health Indicators and Policy Monitoring System for Older Adults (or SISAPIdoso) $)^{13}$, a joint initiative of the Health Coordination of Older Adults (or COSAPI) of the Ministry of Health and the Health Information Laboratory of the Institute of Communication and Scientific and Technological Information (or ICICT) of the Fundação Oswaldo Cruz (the Oswaldo Cruz Foundation, or Fiocruz), during the month of February 2020.

The construction of the model variables consisted of calculating the average of the values recorded over three years, when available, in order to reduce the influence of annual random variability. The plan consists of four action proposals, namely: collective cultural space; public place; family space; institutional space. Each proposal contains actions aimed at each item, and from these proposals, for the evaluation of health indicators, there are the family space and public space items. SISAP-Idoso is therefore regrouped in three pillars for the evaluation of health indicators, to identify:

- Improvements to Family Space (encourage older adults and their families to make spaces of residence more suitable in order to guarantee a "healthy home" with better accessibility and less risk of accidents and falls) - Rate of hospitalizations for older adults due to falls in at least one of the causes (2016-2018 average); Rate of hospitalizations of older adults due to femur fractures (2016-2018 average); Proportion of older adults with difficulty walking at home alone (2013); Mortality rate of older adults due to a fall in at least one of the causes (2016-2018 average);

- Improvements to the Family Space (Training of family caregivers, and State protection for families who are unable to care for their older relatives as mechanisms for preventing intrafamily violence) - Rate of hospitalizations for older adults due to mistreatment in at least one of the causes (2016-2018 average); Mortality rate of older adults due to mistreatment in at least one of the causes (2016-2018 average); Rate of notifications of violence against older adults (2015-2017 average);

- Improvements to the Public Space (as traffic accidents and violence are the biggest specific external cause of death in this age group, it is necessary to better prepare equipment and signs on streets and crossings in cities) - Rate of hospitalizations for older adults due to traffic accidents (2016-2018 average); Mortality rate of older adults due to traffic accidents (2016-2018 average).

Initially, a descriptive analysis was carried out to summarize the data set. This summary was presented through colour-themed maps by quintiles, revealing the situation of each variable by Brazilian state (or Federal District). For the production of the thematic maps, the cartographic base was obtained from the website of the Brazilian Institute of Geography and Statistics (https://ibge.gov.br/) and the Terraview 4.2.2 software package (INPE, 2011, Tecgraf PUCRio / FUNCAT, Brazil) was used.

For the analysis of time trends, the annual percentage change (APC) was estimated for each indicator for Brazil, with a $95 \%$ confidence interval (95\% CI), for each available period. The final model selected was the most adjusted model, with the APC based on the trend of each segment, estimating whether these values are statistically significant $(\mathrm{p}<0.05)$. The significance tests used are based on the Monte Carlo permutation method and on the calculation of the annual percentage variation of the ratio, using the logarithm of the ratio ${ }^{14}$. Statistical analyzes were performed using the Joinpoint Regression Programs, version 4.5.0.0. The exceptions to these analyzes, due to the lack of cases in the historical series, were for the variable "Proportion of older adults with difficulty walking at home alone" for which data were only available for the year 2013, and "Mortality rate of older adults due to mistreatment", for which data were only available for the period 2015-2017. 
A cluster analysis was conducted to determine the level of proximity between the states (or Federal District) in relation to the analyzed indicators. Cluster analysis is a multivariate analysis technique that allows the gathering of objects and/or variables according to their common characteristics. The objective of this technique is to reduce the number of objects, which are inserted in an observation matrix, grouping them in clusters, or in other words, groups of objects according to their similarities, through previously determined similarity criteria ${ }^{15}$. For this case, a cluster analysis with a $27 \times 9$-sized matrix was used, where the objects were grouped (27 states (including the Federal District)). The matrix contained the nine indicators of the Action Plan for tackling violence against older adults provided for in SISAP-IDOSO, in order to support the grouping by states.

Based on the standardization of the variables in Z score, Ward's agglomerative hierarchical method was used. The basic procedure of this method is to compute a distance or similarity matrix between the states (or Federal District), from which a process of successive mergers begins, based on the proximity or similarity between the units. As a measure of similarity between the observations, the square of the Euclidean distance was used and the results are presented in the dendrogram, a tree diagram that shows the groups formed by grouping observations in each step and based on their similarity levels ${ }^{16}$.
To analyze the composition of the clusters and characterize the profiles of violence, the values of each variable were divided into quintiles, and were classified into: 1st quintile (very low), 2nd quintile (low), 3rd quintile (medium), 4th quintile (high), 5 th quintile (very high). The difference between the groups was verified using the Kruskal-Wallis test, considering $p<0.05$. For cluster analysis and the Kruskal-Wallis test, the Statistical Package for the Social Sciences software package version 25.0 (SPSS-25) was used.

This research used secondary data extracted from official sites open to public consultation. Thus, there was no need for appreciation by the Ethics and Research Committee as recommended by Resolution $510 / 2018$ of the National Health Council (or CNS).

\section{RESULTS}

The temporal trend analysis showed that there is a significant trend towards an increase in the number of reports of violence against older adults, hospitalizations of older adults due to mistreatment, hospitalizations of older adults due to fractures of the femur, mortality of older adults due to falls and hospitalizations of older adults due to falls. In relation to traffic accidents, from 2007 there was an increase in hospitalization rates and from 2012 there was a significant reduction in mortality rates due to this cause (Table 1).

Table 1. Temporal trends in the Action Plan indicators for tackling violence against older adults in Brazil: APC, Confidence Interval and JoinPoint Year.

\begin{tabular}{|c|c|c|c|c|c|c|}
\hline Indicator & Data available & APC & $\mathrm{CI} 95 \%$ & $\begin{array}{l}\text { Year } \\
\text { Joinpoint }\end{array}$ & APC & $\mathrm{CI} 95 \%$ \\
\hline Hospitalizations of older adults due to falls & $2000-2018$ & $1.12^{*}$ & $0.6-1.6$ & - & - & - \\
\hline $\begin{array}{l}\text { Hospitalizations of older adults due to femur } \\
\text { fractures }\end{array}$ & $2000-2018$ & $0.70^{*}$ & $0.3-1.1$ & 2015 & 4.2 & $-0.8 ; 9.3$ \\
\hline Mortality of older adults due to falls & $2000-2017$ & $6.62 *$ & $5.8-7.4$ & - & - & - \\
\hline $\begin{array}{l}\text { Hospitalizations of older adults due to } \\
\text { mistreatment }\end{array}$ & $2000-2017$ & $15.31 *$ & $10.1-20.8$ & 2008 & 1.77 & $-2.1 ; 5.8$ \\
\hline Notifications of violence against older adults & 2009-2017 & $61.4^{*}$ & $50.5-70.3$ & 2012 & $10.2^{*}$ & $6.8-13.6$ \\
\hline $\begin{array}{l}\text { Hospitalizations of older adults due to traffic } \\
\text { accidents }\end{array}$ & $2000-2018$ & $-5.58^{*}$ & $-9.5 ;-1.5$ & 2007 & $2.95^{*}$ & $0.8-5.1$ \\
\hline Mortality of older adults due to traffic accidents & $2000-2017$ & $1.53^{*}$ & $0.9-2.2$ & 2012 & $-6.95^{*}$ & $-9.3 ;-4.6$ \\
\hline
\end{tabular}

Source: SISAP-Idoso, 2020. * Statistical significance $p<0.05$; APC: annual percentage change; CI $95 \%, 95 \%$ confidence interval. 
Figure 1 shows the spatial distribution of variables by Brazilian states. It can be seen that there are higher accident mortality rates in the midwest region and higher rates of hospitalizations due to falls and reports of violence in the south and southeast. In general, there is no formation of patterns among the variables, and each variable presents particularities in its distribution (Figure 1).

The analysis of the dendrogram shows the formation of five clusters for the characteristics of violence against older adults (Figure 2). The states that made up cluster 1 had low rates of violence, hospitalization and mortality; Cluster 2 had high hospitalization and mortality rates due to traffic accidents and high mortality rates due to mistreatment, and was formed by the states of Rondônia, Roraima and Tocantins; in Cluster 3, formed by the states of Alagoas, Mato Grosso, Minas Gerais, Paraíba, Pernambuco, Piauí and Rio Grande do Norte, the main characteristic was the high proportions of older adults with mobility difficulties and hospitalizations due to falls; Cluster 4 grouped states with high rates of hospitalization and mortality from falls and fractures and a high rate of violence against older adults; finally, cluster 5 was formed exclusively by the state of Santa Catarina, and had high rates of hospitalization for falls, fractures and mistreatment and high rates of violence ('Table 2).

Figure 3 shows the comparison of the values of each analyzed variable between the clusters formed. There was a significant difference between the clusters for the variables proportion of older adults with difficulty walking at home alone, hospitalization rate of older adults due to traffic accidents, hospitalization rate of older adults due to femur fractures, hospitalization rate of older adults due to mistreatment and hospitalization rate of older adults due to falls, showing that these variables best discriminated against clusters (Figure 3). 


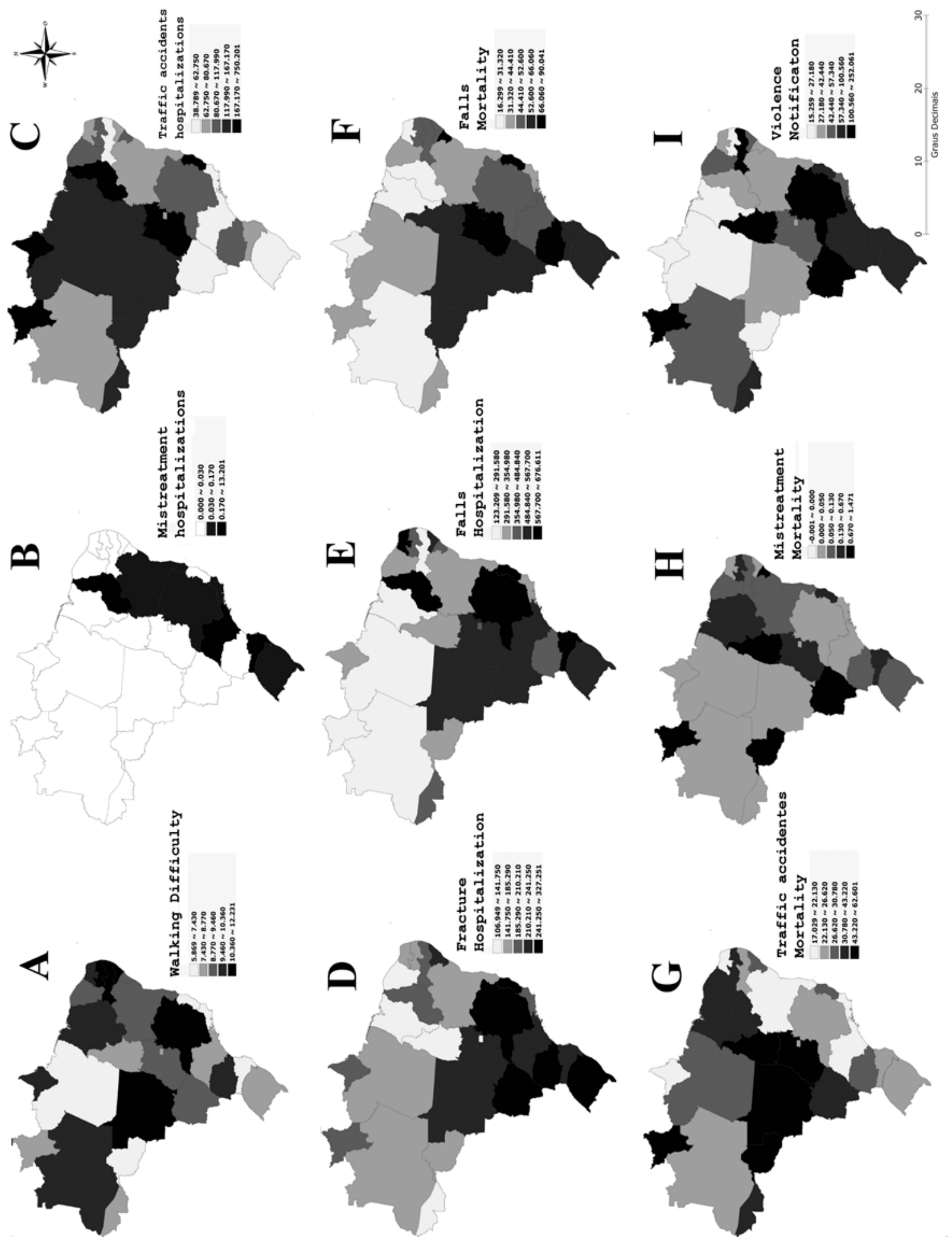

Figure 1. Spatial distribution by state (including the Federal District) of the indicators that make up the Action Plan for tackling violence against older adults in Brazil.

Figure A: Proportion of older adults with difficulty walking at home alone; Figure B: Rate of hospitalizations for older adults due to mistreatment; C: Rate of hospitalizations of older adults due to traffic accidents; D: Rate of hospitalizations of older adults for fractures of the femur; E: Rate of hospitalizations of older adults due to falls; F: Mortality rate of older adults due to falls; G: Mortality rate of older adults due to traffic accidents; $\mathrm{H}$ : Mortality rate of older adults due to mistreatment; I: Rate of notifications of violence against older adults. 


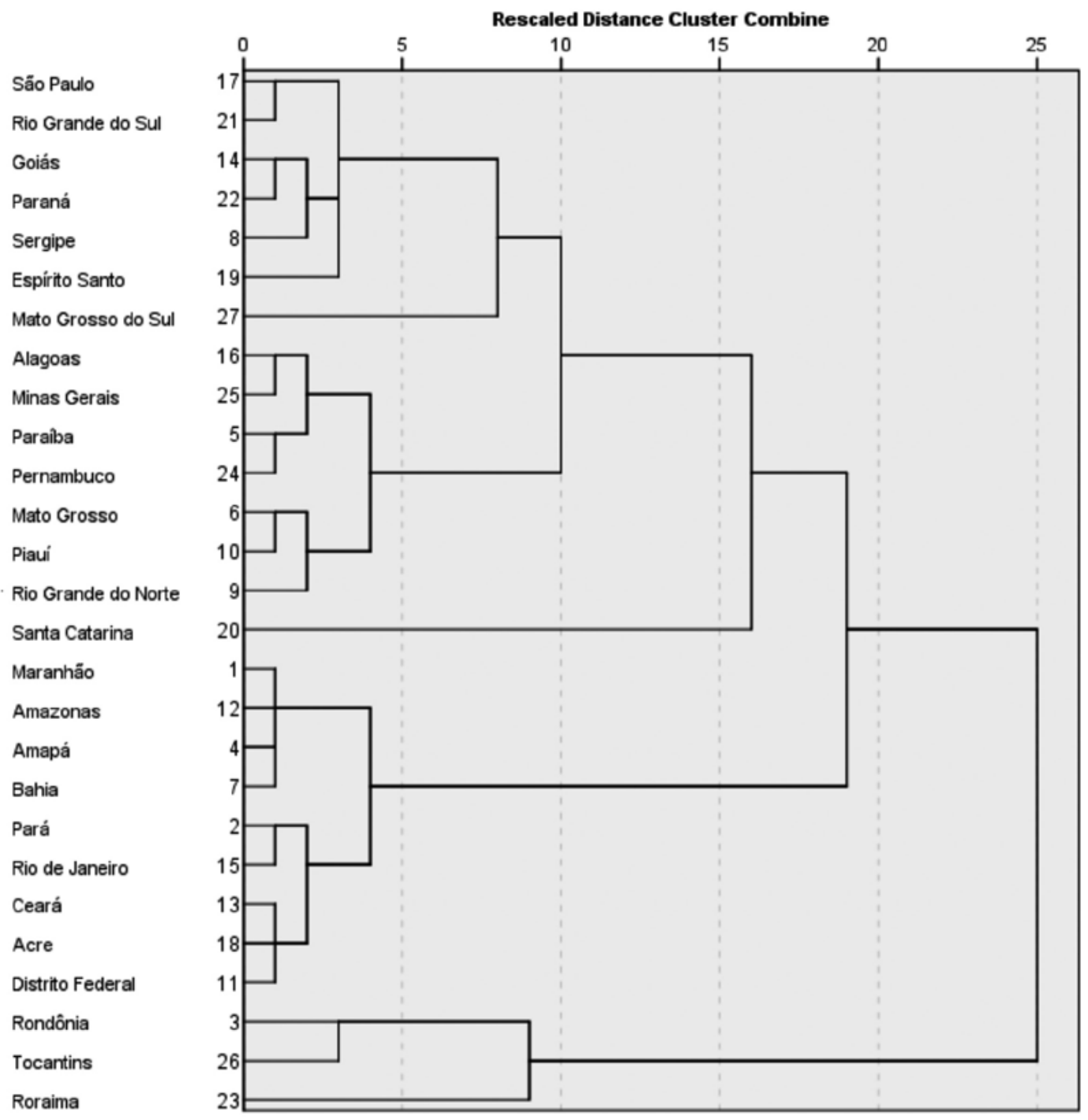

Figure 2. Dendrogram representing the Cluster analysis based on the variables that make up the Action Plan for tackling violence against older adults in Brazilian states (including the Federal District). 


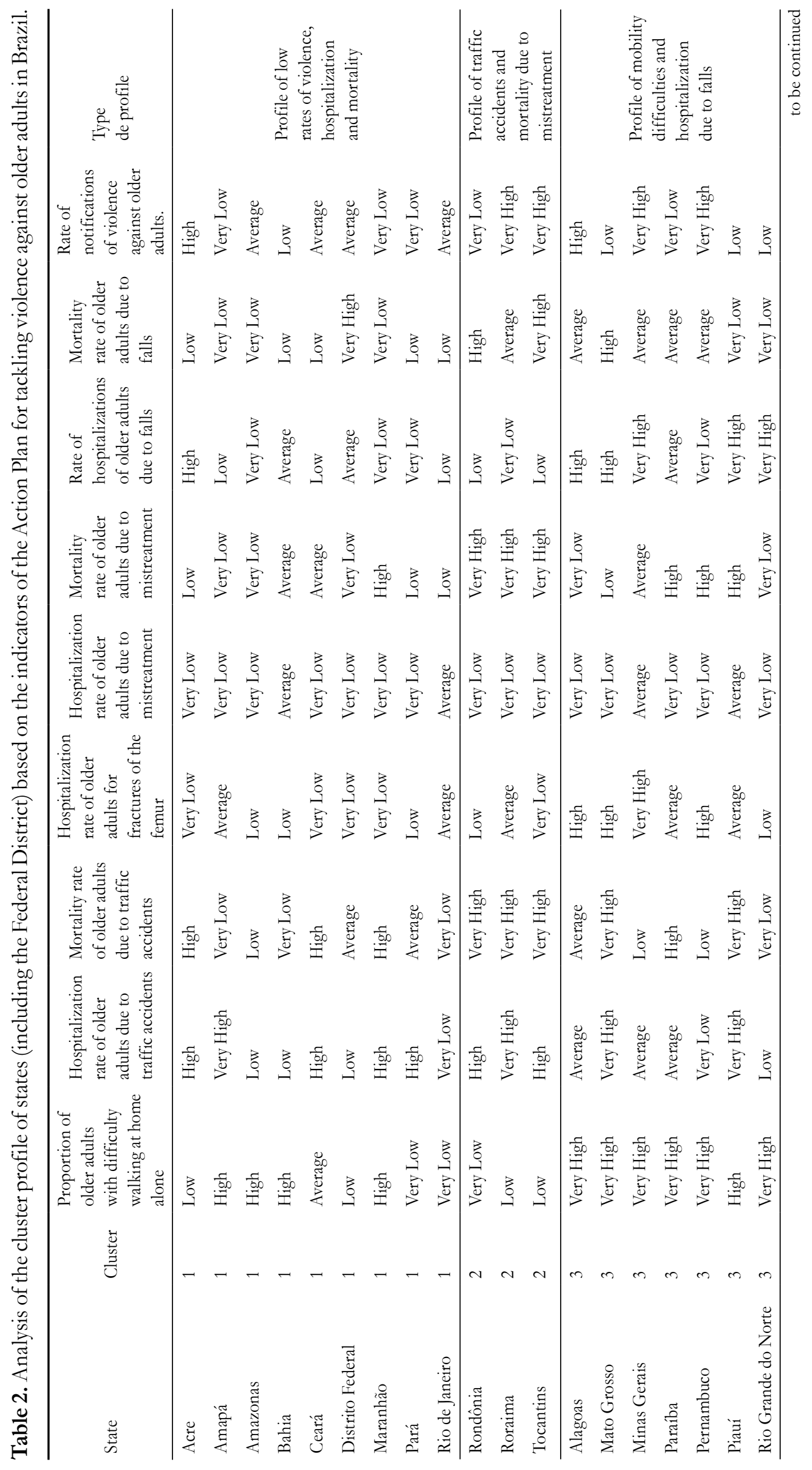




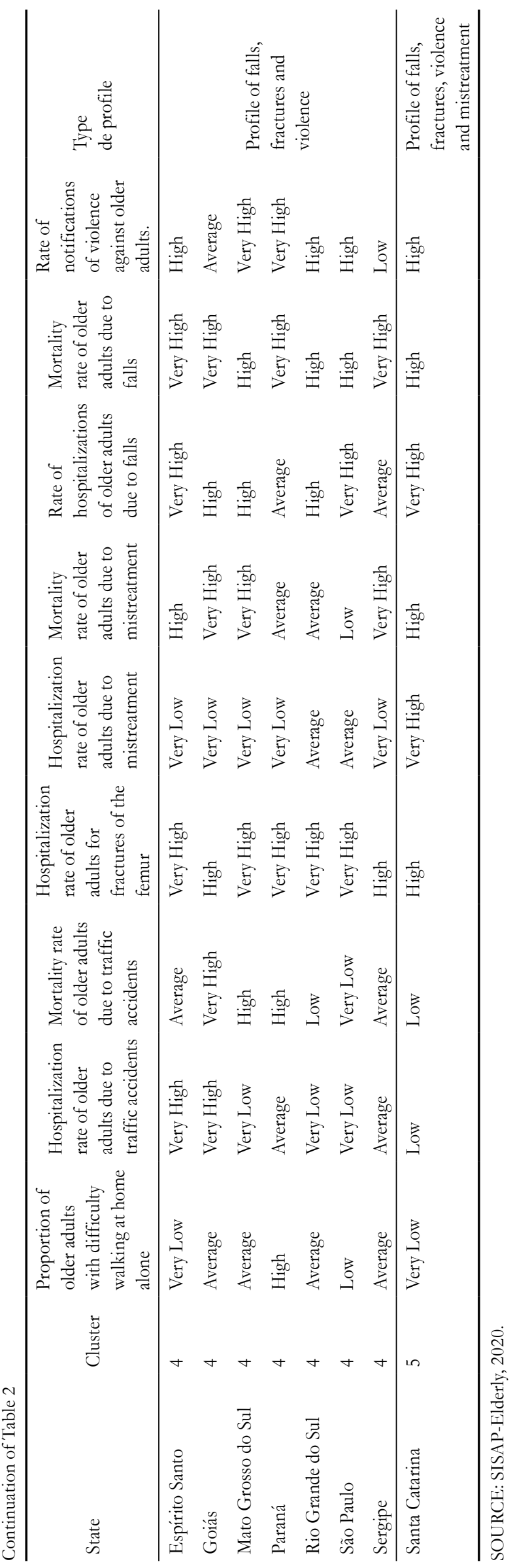



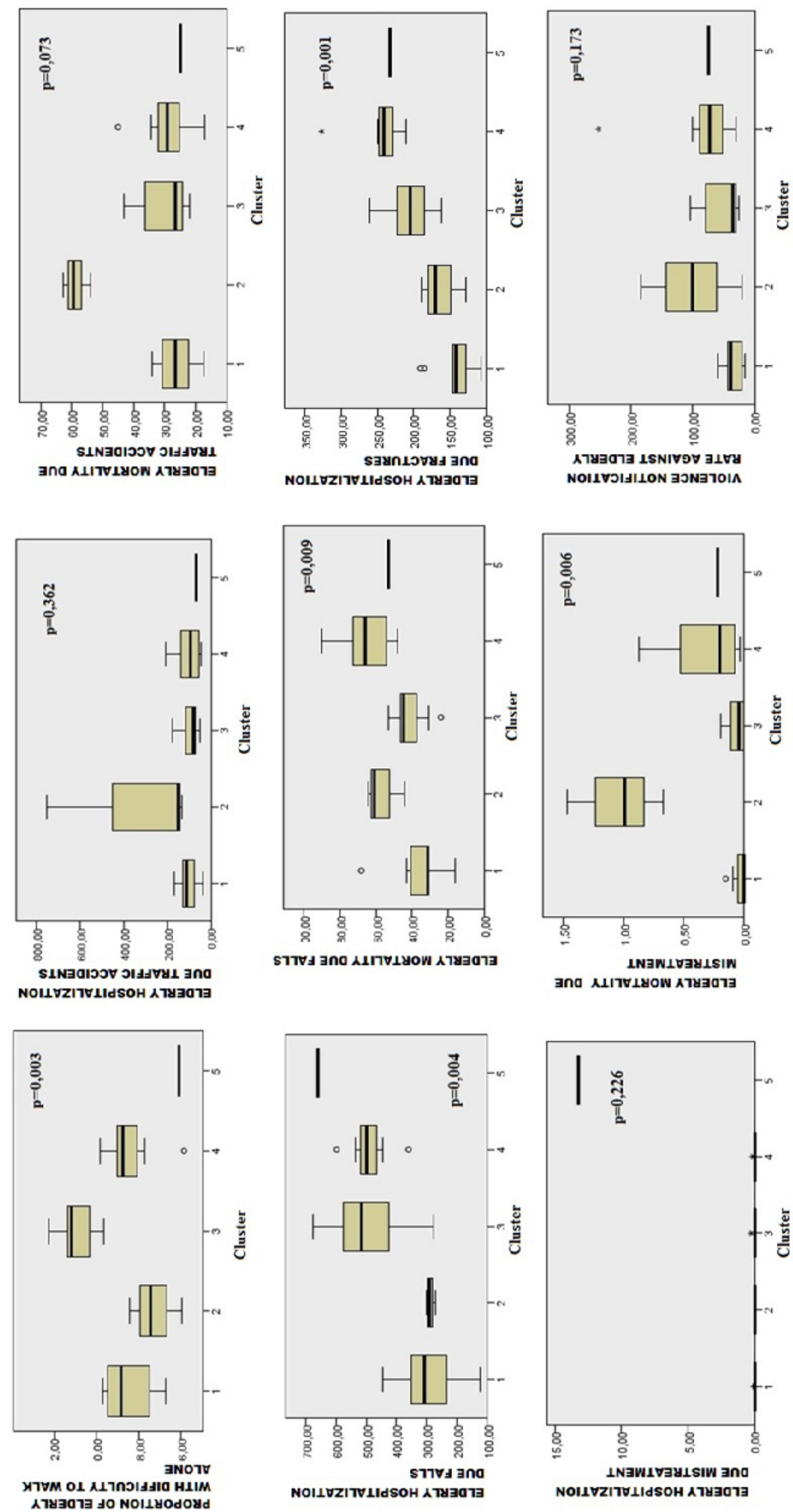

Figure 3. Box Plot and statistical significance of the comparison between the clusters for the values of each variable that make up the Action Plan for tackling violence against older adults in Brazil. 


\section{DISCUSSION}

The socio-historical identity of old age has been constructed across different eras. There are records of violence and mistreatment dating back to Ancient Greece, but it was at the beginning of the 20th century when there was a (re)emergence of the social devaluation of old age, the result of phenomena such as industrialization, urbanization, technological advancement, patriarchy, neoliberalism, among other factors, contributing to the creation of a "social statute of dependence in old age" 17 .

From the analysis of the results, it was observed that there is an increasing trend in the number of reports of violence against older adults, hospitalizations of older adults due to mistreatment, hospitalizations of older adults due to fractures of the femur, mortality of older adults due to falls and hospitalizations of older adults due to falls. To understand this phenomenon, it is necessary to understand the factors that are related to violence against older adults, which have already been described in studies with this population. Older adults who are dependent for instrumental activities of daily living such as home care and management of their environment, are frequent victims of violence ${ }^{18}$. In this sense, the more dependent on their caregiver they become, the more susceptible to violence older adults can be ${ }^{19}$.

Violence against older adults has begun to be understood as a public health and criminal justice problem in contemporary times ${ }^{20}$. In addition to the increase in notifications of violence, it is also necessary to assess the growing trend of hospitalizations for abuse. The actual incidence and prevalence of hospitalization for the mistreatment of older adults is unknown, as most cases are underreported. However, this upward trend may be associated with more effective reporting, also linked to the existence of legal mechanisms that establish its necessity ${ }^{21}$, such as the Statute for Older Adults and the Policy to Tackle Violence Against Older Adults. Estimates reveal that there are approximately 450,000 new cases of violence against older adults each year in the USA, with an overall prevalence of $10 \%$. These values are alarming if it is considered that for each accounted case, there are five that are not reported ${ }^{22}$.
In the context of Latin America, the countries with the highest rates of violence are: Colombia, Brazil and Panama, respectively. In Argentina and Chile, the problem is also growing, as more than 30,000 older adults were victims of mistreatment in 2009 alone $^{23}$.

A study published in 2018 evaluated the time trend of hospitalization and mortality from falls in older adults in Brazil, finding that in the period from 1996 to 2012 there were 66,876 deaths from falls and 941,923 hospitalizations with secondary diagnosis associated with such accidents in older adults in the country. In addition, the authors found that 32.3\% of these deaths and $21.2 \%$ of these hospitalizations in the historical series occurred in Brazilian state capitals. The mortality rate of older adults due to falls in Brazilian capitals increased $200 \%$, from 1.25 to $3.75 / 10,000$ older adults, with an increase of $15 \%$ per year, between 1996 and $2012^{24}$. The increase in these indicators within the historical series evaluated is justified by the authors by the increase of 8.5 million people aged 60 and over, with a greater increase in the southeast, northeast and midwest, followed by the south and north regions ${ }^{25}$.

The upward trend identified in this study is also associated with the demographic transition that exists in Brazil. Population aging is a phenomenon that occurs worldwide, and falls are among the diseases that most affect the older adult population ${ }^{26}$. Mortality from falls among older adults has also increased in other countries, with emphasis on developed countries, such as the USA ${ }^{27}$.

Types of violence, however, have a heterogeneous distribution, as do the factors associated with them, depending on the social, political, cultural and geographic space in which they are inserted. In one study, different prevalence rates were estimated across continents, with a prevalence of $20.2 \%$ in Asia, $15.4 \%$ in Europe and $11.7 \$$ in the Americas. The authors stated that rates may vary by type of violence, and depending on the country, state or municipality ${ }^{4}$.

In the present study, the spatial distribution of the rates of each specific type of violence showed that there is a regional distribution pattern of 
the indicators analyzed. It was observed that the highest rates of notification for violence, as well as hospitalizations for falls, fractures, difficulty walking alone, and hospitalizations for mistreatment were found in the southeast region.

Researchers evaluated hospitalization and mortality from falls among older adults in Brazil, and found that the midwest region had the highest average rates in the period for mortality and hospitalization. This finding corroborates the results of the present study ${ }^{24}$. Some questions are raised about these differences in rates of hospitalization and mortality due to falls among Brazilian regions, as external environments are directly associated with the occurrence of falls, through poor street paving, signs and high sidewalks, and poorly organized public transport does not facilitate its use by older adults $^{28}$. In addition to these factors, the authors also associate the environment around older adults, such as staircases without support, uneven or unpaved floors, slippery surfaces, non-fixed rugs and poorly lit environments, with the problem of falls ${ }^{29}$.

A study that analyzed the rates of hospitalization and mortality due to aggression in patients over 60 years old, identified that the southeast region presented the highest rates of hospitalization for this reason and the second highest mortality rate due to this cause. The authors argue that these results suggest the need for greater investment in social and health issues, but it must also be considered that the population of the southeast has the highest density of individuals in Brazil, including older adults ${ }^{30}$.

When explaining these regional differences it is important to consider the characteristics of the social conformation of each region, highlighting the intra-individual dynamics, the intergenerational transmission of violence, the levels of dependency between older adults and their caregivers, external stress and social isolation. These are theories already widely reported in literature to try to explain the factors with the potential to lead to violent practices against older adults ${ }^{31}$.

The present study identified the relationship between the types of violence through the clustering of indicators, evidenced by the construction of the dendrogram (Figure 2) and the classification of indicators for each state (Table 2).

The analysis of national-level indicators related to violence corresponds to the first of the steps to redesign the service for older individuals, the results of which are reflected in the assessment of declining needs and capacities. The following steps suggest the definition of objectives, the implementation of hospital care plans, ensuring a referral pathway for different levels of health care and involving communities and caregivers in the care and attention process ${ }^{32}$.

Government strategies to tackle this phenomenon have been implemented in developed countries since the $1980 \mathrm{~s}^{33}$. In Brazil, the theme began to appear on the public agenda with the advent of the National Policy for the Reduction of Morbidity and Mortality due to Accidents and Violence, in 2001, and the Statute of Older Adults, in 2003, and was incorporated in the National Health Policy for Older Adults, the National Policy for Emergency Care, the National Policy for People with Disabilities, and the Pact for Health?.

Due to the particularities related to reports of violence in older adults, which are often related to family members and caregivers ${ }^{7}$, health indicators are considered strategies for planning and managing health policies.

These indicators are mostly related to hospital care, and it is therefore suggested that the topic in question is also a subject related to Primary Care, the gateway to the Health Care Network.

Given the regional distribution of the care network of Brazilian health services, as well as the cultural variables closely linked to the prevalence of violence, it is important that Primary Care effectively coordinates prevention actions according to local realities. There is evidence of the potential for interventions within the scope of Primary Care in this sense $e^{34}$.

Limitations of the present study include the characteristics inherent to the methodological design, such as the impossibility of generalizing the aggregated 
results to an individual level, and the underreporting of records of violence against older adults.

\section{CONCLUSION}

The temporal trend analysis showed that there is a significant trend of an increase in the number of reports of violence against older adults, hospitalizations of older adults due to mistreatment, hospitalizations of older adults due to fractures of the femur, mortality of older adults due to falls and hospitalizations of older adults due to falls. This trend accompanies the development of the demographic transition in Brazil and around the world. This increase, however, does not exhibit a spatial pattern among Brazilian regions.

Despite the absence of a spatial relationship, the formation of clusters provides support for states to rethink the shaping of their policies in an intersectoral manner, since the phenomenon of violence against older adults is related not only to variables connected to the individual, but also to the context, demanding articulation between different sectors.

Notification strategies should also be intensified, with a view to reducing possible weaknesses in complaints and notifications of violence against older adults in Brazil, thus improving the shaping of statistical models to support government decisionmaking and reduce morbidity and mortality related to such traumas.

At the national coordination level, plans and programs dedicated to older adults should take into account the multiple approaches to violence, as well as their regional trends, especially in the context of developing countries, which are experiencing different phases of the demographic transition.

Edited by: Ana Carolina Lima Cavaletti

\section{REFERENCES}

1. Minayo MCS. Violência e saúde. Rio de Janeiro: FIOCRUZ; 2006.

2. Alencar FO, Moraes JR. Prevalência e fatores associados à violência contra idosos cometida por pessoas desconhecidas, Brasil, 2013*. Epidemiol Serv Saúde. 2018;27(2):e2017186 [10p.].

3. Williams JL, Davis M, Acierno R. Global prevalence of elder abuse in the community. In: Dong X, editor. Elder abuse: research, practice and policy. New York: Springer International Publishing; 2017. p. 720.

4. Yon Y, Mikton CR, Gassoumis ZD, Wilber KH. Elder abuse prevalence in community settings: a systematic review and meta-analysis. Lancet. 2017;5(2):147-56.

5. Lopes EDS, Ferreira AG, Pires CG, de Moraes MCS, D’Elboux MJ. Elder abuse in Brazil: an integrative review. Rev Bras Geriatr Gerontol. 2018;21(5):628-38.

6. Closs VE, Schwanke CHA. A evolução do índice de envelhecimento no Brasil, nas suas regiões e unidades federativas no período de 1970 a 2010. Rev Bras Geriatr Gerontol. 2012;15(3):443-58.

7. Miranda GMD, Mendes ACG, da Silva ALA. Desafios das políticas públicas no cenário de transição demográfica e mudanças sociais no Brasil. Interface. 2016;21(61):309-20.

8. Teixeira C, Silveira P. Glossário de análise política em saúde. Salvador: UFBA; 2016.

9. Veras RP, Oliveira M. Envelhecer no Brasil: a construção de um modelo de cuidado. Ciênc Saúde Colet. 2018;23(6):1929-36.

10. Camacho ACLF, Alves RR. Mistreatment against the elderly in the nursing perspective: an integrative review. J Nurs UFPE. 2015;9(2):927-35.

11. Contandriopoulos AP, Champagne F, Denis JL, Pineault R. A avaliação na área da saúde: conceitos e métodos. In: Hatz ZMA, da Silva LMV. Avaliação em saúde: dos modelos teóricos à prática na avaliação de programas e sistemas de saúde. Rio de janeiro: Fiocruz; 1997. p. 132.

12. Brasil. Ministério da Saúde. Sistema de Indicadores de Saúde e Acompanhamento de Políticas do Idoso. Brasília, DF: MS; 2020.

13. Fundação Oswaldo Cruz, Instituto de Informação e Comunicação Científica e Tecnológica em Saúde. Sistema de Indicadores de saúde e Acompanhamento de Políticas Públicas do Idoso (SISAP-Idoso). Rio de Janeiro: FIOCRUZ; 2011.

14. Kim HJ, Fay MP, Feuer EJ, Midthune DN. Permutation tests for joinpoint regression with applications to cancer rates. Stat Med 2000;19(3):335-51. 
15. Corrar LJ, Paulo E, Dias FJM. Análise Multivariada. São Paulo: Atlas; 2007.

16. Ribeiro CPP, Abrantes LA, Vale SJ. Desenvolvimento municipal: uma análise multivariada para os municípios mineiros. In: Anais do $21^{\circ}$ Congresso Brasileiro de Custos-ABC;17-19 nov. 2014; Natal. Natal: ABC; 2014. p. 1-16.

17. Dias I. Envelhecimento e violência contra os idosos. Sociologia. 2005;25(1):249-73.

18. Duque AM, Leal MCC, Marques APO, Eskinazi FMV. Violência contra idosos no ambiente doméstico: prevalência e fatores associados (Recife/PE). Ciênc Saúde Coletiva. 2012;17(8):2199-2208.

19. Holanda A, Queiroz A, Mendonça B, Monteiro B, Nogueira D, Barros E, et al. A percepção da violência por idosos do grupo viva melhor de um municipio goiano. Rev Eletr Fac Montes Belos. 2016;9(1):173-83.

20. Krug EG, Dahlberg LL, Mercy JA, Zwi AB, Lozano $\mathrm{R}$. World report on violence and health. Geneva: WHO; 2002

21. Young LM. Elder physical abuse. Clin Geriatr Med. 2014;30:761-8.

22. Lachs MS, Pillemer KA. Elder abuse. N Engl J Med. 2015;373:1947-56

23. Burnett J, Achenbaum WA, Murphy KP. Prevention and early identification of elder abuse. Clin Geriatr Med. 2014;30:743-59.

24. Abreu DRDOM, Novaes ES, Oliveira RRD, Mathias TADF, Marcon SS. Internação e mortalidade por quedas em idosos no Brasil: análise de tendência. Ciênc Saúde Colet. 2018; 23(4):1131-41.

25. Fact Sheets n ${ }^{\circ}$ 344: Falls. Geneva: World Health Organization; 2012.
26. Meschial WC, Soares DFPP, Oliveira NLB, Nespollo AM, Silva WA, Santil FLP. Elderly victims of falls seen by pre hospital care: gender differences. Rev Bras Epidemio.1 2014;17(1):3-16.

27. Hu G, Baker SP. An Explanation for the recent increase in the fall death rate among older americans: a subgroup analysis. Public Health Rep [Internet]. 2012 [acesso em 26 mar. 2020];127(3):275-81. Disponível em: http://journals.sagepub.com/ doi/10.1177/003335491212700307

28. Guerra HS, Bernardes DCF, Santana JA, Barreira LM. Prevalência de queda em idosos na comunidade. Rev Saúde Pesqui. 2016;9(3):547-55.

29. Morsch P, Myskiw M, Myskiw JC. A problematização da queda e da identificação dos fatores de risco na narrativa de idosos. Ciênc Saúde Colet. 2016;21(11):1-10.

30. Souza CS, Bandeira LLB, Naspolini MM, Marcolla V, Souza NJD. Análise das taxas de internação e de mortalidade por agressão em pacientes com mais de 60 anos. Rev Soc Bras Clín Méd. 2018;16(2):89-93.

31. Wolf RS, Pillemer K. Elder abuse and case outcome. J App Gerontol. 2000;19(2):203-20.

32. Curcio CL, Payán-Villamizar C, Jiménez A, Gómez F. Abuse in Colombian elderly and its association with socioeconomic conditions and functionality. Colomb Med. 2019;50(2):77-88.

33. Thiyagarajan JA, Araujo CI, Peña-Rosas JP, Chadha S, Mariotti SP, Dua T, et al. Redesigning care for older people to preserve physical and mental capacity: SHO quidelines on community-level interventions in integrated care. PLoS Med 2019;16(10): e1002948 [10 p.].

34. Mohd MFH, Yuen CW, Othman S. The Effectiveness of educational intervention in improving primary health-care service providers' knowledge, identification, and management of elder abuse and neglect: a systematic review. Trauma Violence Abuse. 2019:1-10. 